\title{
THE IMPACT OF SEASONALITY IN TEMPERATURE FORECAST ON TOURIST ARRIVALS IN BANGLADESH: AN EMPIRICAL EVIDENCE
}

\author{
Sayed Mohibul HOSSEN \\ Universiti Sains Malaysia, School of Mathematical Science, 11800 USM Penang Malaysia, \\ Mawlana Bashani Science and Technology University, Department of Statistics, Tangail 1902, Bangladesh, e-mail: m300cht@ gmail.com
}

Mohd Tahir ISMAIL

Universiti Sains Malaysia, School of Mathematical Science, 11800 USM Penang, Malaysia, e-mail: m.tahir@usm.my

Mosab I. TABASH*

Al Ain University, College of Business, P.O. Box: 64141 Al Ain, United Arab Emirates, e-mail: mosab.tabash@aau.ac.ae

Citation: Hossen, S.M., Ismail, M.T., \& Tabash, M.I. (2021). THE IMPACT OF SEASONALITY IN TEMPERATURE FORECAST ON TOURIST ARRIVALS IN BANGLADESH: AN EMPIRICAL EVIDENCE. GeoJournal of Tourism and Geosites, 34(1), 20-27. https://doi.org/10.30892/gtg.34103-614

\begin{abstract}
In the present study, we aim to investigate how seasonality influences the climate changes on the outdoor thermal comfort for traveling to visit Bangladesh. Wherein, the effect of temperature on tourist arrival is assessed using SANCOVA and SARIMA model at seven attractive sightseeing diverse places in Bangladesh. The highest temperature has appeared in Khulna and Rajshahi with $35.53{ }^{\circ} \mathrm{C}$ and $35.85{ }^{\circ} \mathrm{C}$ and the lowest temperature was appeared in Rajshahi and Rangamati with $10.40{ }^{\circ} \mathrm{C}$ and $11.72{ }^{\circ} \mathrm{C}$, respectively. This result also revealed that the temperature for Dhaka, Chittagong, Cox's Bazar, Khulna, and Sylhet has extreme values of decreasing, in Dhaka the temperature will be $25.140{ }^{\circ} \mathrm{C}$ on January 2023 , in Chittagong $260{ }^{\circ} \mathrm{C}$ on January 2027, Cox's Bazar $26.490{ }^{\circ} \mathrm{C}$ on January 2030, in Khulna $25.610{ }^{\circ} \mathrm{C}$ on January 2023 , and in Sylhet $26.560{ }^{\circ} \mathrm{C}$ on January 2020. Our findings also indicate that the tourism industry of Bangladesh is more vulnerable to seasonal variation and this seasonality has a $74 \%$ effect on tourist's arrival as well as a $98 \%$ effect on overall temperature in Bangladesh.
\end{abstract}

Key words: seasonality, temperature, modeling, forecasting, SANCOVA model, SARIMA model

$* \quad * \quad * \quad * *$

\section{INTRODUCTION}

"Tourism" is associated with the stays rendered by people other than their normal environment (Pablo-Romero et al., 2017). In raising economic sector, tourism is the fastest-growing segment in the world. It plays a significant role in many national and local economies (Fyfe et al., 2020). According to the World Travel \& Tourism Council's (WTTC) investigation, it is visible that this sector contributes $10.4 \%$ of collective GDP and 10\% of total service, or 319 million careers, in 2018 (WTTC, 2019). Climate has a significant effect on the tourism resources, tourism zone, tourism seasons, tourism supply and demand, etc (Fang and Yin, 2015). For destination selection, they are not only influential factors but are also important in altering activities and travel plans, during the trip. Temperature is one of the most crucial factors in climatic variables for tourism in summer and bones trembled in winter tourism (Wilkins et al., 2018). Nice weather conditions encourage outdoor tourists and entertaining activities and thus play a key role in the choice of tourism destinations (Grillakis et al., 2016).

\section{LITERATURE REVIEW}

From the view of the tourism industry, it is generally assumed that the climate of places greatly influences the likings and pleasure of tourists (Kovács et al., 2016; Witchayakawin et al., 2020 ). Due to its seasonality, this issue determines the availability and quality of certain open-air recreational activities (Hewer et al., 2016). Climate change may affect short-term and long-term cost repercussions for the tour operators and economies reliant on tourism (Dube and Nhamo, 2018). Climate variables such as temperature compete a vital role in tourism flows worldwide. This enhances tourism at the forefront of the economic segments to be affected by climate change (Pintassilgo et al., 2016). It is identified as a motivator factor for travel, in the area of tourism research (Li et al., 2018).

Tourists want to travel to a wide diversity of environments, including urban and isolated regions (Priego et al., 2015). It is dangerous and unpleasant to hike or involve in energetic hard work during high temperatures (Hoogendoorn and Fitchett, 2018). But it has a positive impact on the tourists in large numbers and feels enjoyable environments on an outing in cool areas (Jedd et al., 2018). Therefore, climatic resources contribute significantly to tourists' decision-making processes, travel, as well as the related allocation of tourism expenditures (Scott et al., 2016). Different types of tourism, such as tourism for beaches and natural sights are vastly affected by seasonality as it is considered as an input in designing the tourism product, such as wintertime sports, and water sports (Li et al., 2017). Climatic variables have an important effect as well as a significant relationship with the tourism stakeholders to choose the destination and planning to travel in different seasons (Zhang and Kulendran, 2017). Therefore, seasonality is an essential issue that should be addressed at policy, marketing, and operation levels.

Tourist destinations have begun to identify the complexities of destination, attractiveness, climate change, and develop strategic plans (Becken et al., 2015). The feasibility of forecasting depends on the instant application of a surveillance system (Pasetto et al., 2017). So, the importance of temperature prediction is addressed in several studies. Chen et al. (2017) used the SARIMA model to analyze the monthly mean temperature in Nanjing, China. Naing and Htike (2015) carried out a study to forecast Malaysian monthly temperature using random forests. Research has also been undertaken on the impact of weather on tourist activities, tourist satisfaction, and tourist safety. Temperature and rainfall fluctuations of West Bengal and Assam, India has been analyzed and forecast by using the ARIMA model (Pratiher et al., 2016; Patowary, 2017). Historical and memorials, a lot of resorts, lovely beaches, natural picnic spots, green forest, tea plantation, and different tribal people in hill tracts are the main attractions for the visitors in Bangladesh. In the country's north, it includes the biggest and most ancient archaeological site, the Buddhist monastery, and the temple city in Rajshahi. The south-east of Bangladesh features

\footnotetext{
${ }^{*}$ Corresponding author
} 
natural and hilly, such as the Chittagong Hill Tracts, including a lot of natural lakes and beaches, along with the longest sea beaches in the world, at Cox's Bazar. South-west Bangladesh boasts, Sundarbans, includes the largest mangrove forest in the world, as well as royal Bengal tigers, mottled deer, and the historically important Sixty Dome Mosque in Khulna. There are green tea plantations on small hills and natural national forests with wildlife are in the Sylhet division, the north-eastern part of Bangladesh. Natural waterfalls and migratory birds in the haor (wetlands) areas are also popular attractions during winter. However, the temperature forecast potentially influences the tourist destination for touring Bangladesh's tourist attractions.

Again, when we do forecast about any specific issue of a country such as war, flood, and pandemic, etc. then people from outside assume that the whole country is under crisis. Maybe some parts of the country are affected so we cannot say the whole situat ion is not in favour of traveling. Also, travellers spend their holidays for not a long period, and it is difficult to visits all the attractive tourists' spots within a short period of traveling. Besides these travellers from the different parts of the world are not the same in choice. Some like summer, some prefer rainy, and some love the winter season for traveling. Therefore, the main objective of this research is to find out the relation between seasonality in climate change and the tourism industry in Bangladesh. So far in our knowledge, there is rare studies have been applied to the SARIMA model to evaluate the temperature forecast on selecting the tourist destination in Bangladesh.

Rahman et al. (2017) have applied the ARIMA model for the future projection of climate change in Bangladesh. Wavelet-ARIMA model has been used by Nury et al., (2017) to measure the temperature of the northeastern part of Bangladesh. It is therefore our aim in this study was to determine the influences of the climatic variables on the outdoor thermal comfort for traveling to visit Bangladesh. Wherein, the effect of temperature on seven geographically diverse tourists' destinations in Bangladesh, was assessed by using SARIMA and SANCOVA model. More specifically to examine the impact of seasonality on tourist's arrival that contribute to the national economy of Bangladesh. More additionally some like beaches, some prefer archaeological sites, some want to spend in nature, and some loves adventure in hilly and forest area. So, another major aim is to model and forecasting the climatic variable of differen t tourists' spots of Bangladesh that might be helpful for travellers to discover Bangladesh in their convenient time and comfortable climatic variable all year-round. Which makes the wheel of the tourism industry active and profitable all year round.

\section{METHODOLOGY}

Study Area and data collection

The climate of Bangladesh splits the year usually into three seasons: between May to October is the monsoons or wet season; from October to February is called cool season; and the dry season between March to May. In a sense of comfort, it is better to visit in the cool season to discover Bangladesh. There is heavy rainfall at the time of monsoon season which makes it difficult to travel in some tourist areas. Primary data has not been used because it would take a lot of time and employs complicated mental exercise, so secondary data is used in the study. By realizing this, we collect temperature data for tourists' stations from Bangladesh Agricultural Research Council (BARC) and Bangladesh Meteorological Department (BMD). Monthly maximum and minimum temperature data of capital of Bangladesh, Dhaka, the northern part (Rajshahi), in the south-eastern part (Chittagong, Cox's Bazar \& Rangamati), the south-western part (Khulna), and the northeastern part (Sylhet) in Bangladesh are taken as study variables as shown in Figure 1.

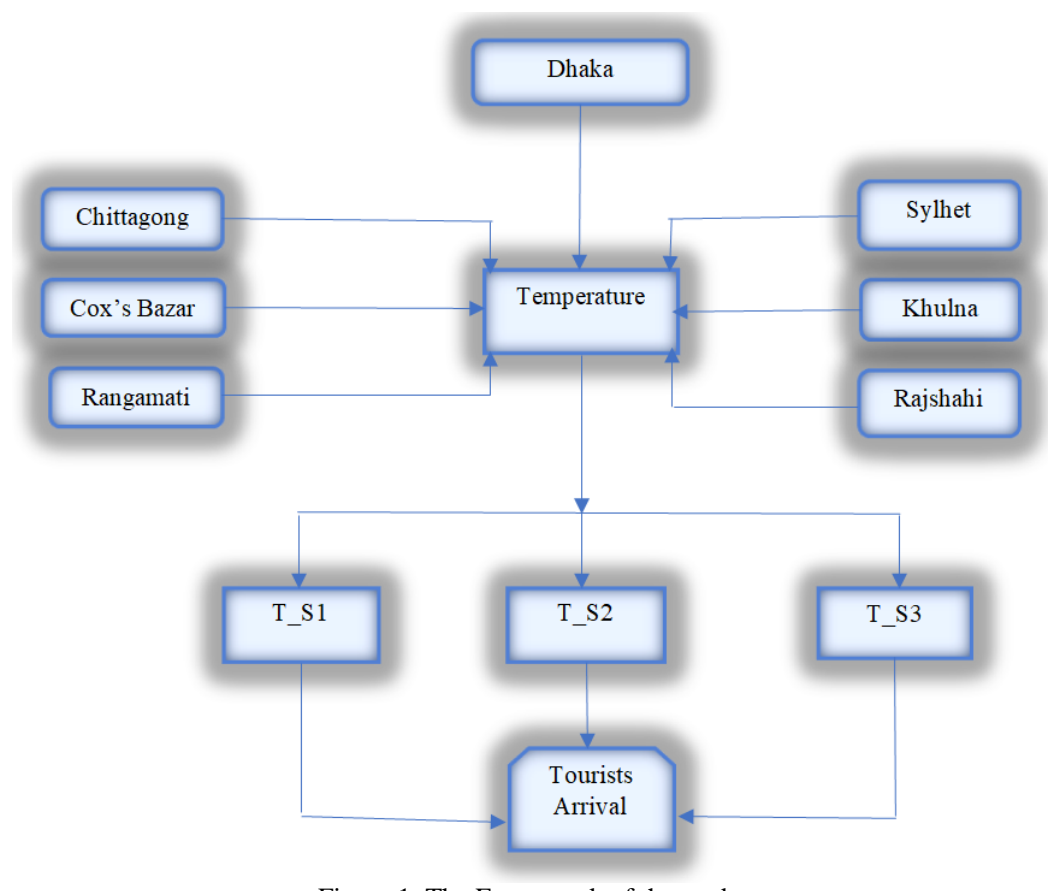

Figure 1. The Framework of the study

At first, we screen the missing values. We exclude the station from the modeling, which includes more than $2 \%$ missing value. Identification is another checking, for an equal amount of temperature along the year in the consecutive month. After checking and passing the above tests of these seven stations containing long-term data (more than 40 years) up to 2018 were used in this research. Therefore, maximum, and minimum temperature data from January 1972 to December 2018 was used for these stations.

\section{Procedure of SARIMA Model}

The present observation in the Autoregressive (AR) procedure of order $\mathrm{p}$, is created by a weighted normal of past observations returning p periods together with parameters $\phi_{1}, \phi_{2 v^{n x},} \phi_{p}$ and organized with a random disturbance in the present time frame. We indicate this procedure as $\operatorname{AR}(\mathrm{p})$ and compose the equation as, 


$$
y_{t}=c+\phi_{1} y_{t-1}+\phi_{2} y_{t-2}+\ldots+\phi_{p} y_{t-p}+\varepsilon_{t}
$$

Every observation in the Moving Average (MA) procedure of order q is created by a weighted average of random disturbance returning to q periods with parameters $\theta_{1}, \theta_{2}, \cdots, \theta_{q}$. For indicating, we write this procedure as MA (q) and compose the equation as,

$$
y_{t}=\mu+\varepsilon_{t}+\theta_{1} \varepsilon_{t-1}+\theta_{2} \varepsilon_{t-2}+\ldots+\theta_{q} \varepsilon_{t-q}
$$

With moving average error terms, the Autoregressive schemes of the form are denoted by-

$$
y_{t}=c+\phi_{1} y_{t-1}+\phi_{2} y_{t-2}+\ldots+\phi_{p} y_{t-p}+\varepsilon_{t}+\theta_{1} \varepsilon_{t-1}+\theta_{2} \varepsilon_{t-2}+\ldots+\theta_{q} \varepsilon_{t-q} \ldots
$$

The above procedure is called ARMA (p, q) or Autoregressive Moving Average (ARMA) process of order (p, q). In general, if a time series is $\mathrm{I}(d)$, then after differencing it $\boldsymbol{d}$ times we get an $\mathrm{I}(0)$ i.e., stationary. Therefore, if we take difference a time series $\boldsymbol{d}$ times and then apply the ARMA $(p, q)$ model to it, then the time series model is ARMA $(p, d, q)$.

Therefore, the ARIMA $(p, d, q)$ the process can be written as:

$$
\Delta^{d} y_{t}=\phi_{1} \Delta^{d} y_{t-1}+\ldots+\phi_{p} \Delta^{d} y_{t-p}+\varepsilon_{t}+\theta_{1} \varepsilon_{t-1}+\ldots+\theta_{q} \varepsilon_{t-q}
$$

Where, $\epsilon$ and $\mu$ are constant $\varepsilon_{t}$ is assumed to be a normal random variable with 0 mean and variance $\sigma_{\varepsilon}{ }^{2}$

$p=$ number of autoregressive terms and $q=$ number of moving average terms

$d=$ number of differencing

$\varepsilon_{t-1}, \varepsilon_{t-2}, \ldots, \varepsilon_{t-q}=$ errors in previous time periods

$\Delta y_{t}=y_{t}-y_{t-1}, \Delta^{d}$ indicates the $d$ th difference of $y_{t}$ and $\Delta y_{t-1}=y_{t-1}-y_{t-2}$ are the first differences of $y_{t}$ and so on.

Where $\Delta^{d}$ indicates the $d$ th difference of $y_{t}$. If the data shows a strong seasonal pattern, this indicates a high correlation between values observed during the same season in consecutive years. Considering $(p, d, q)$ is the nonseasonal part and $(P, D, Q) s$ is the seasonal part of the model then the Seasonal ARIMA model can be labeled as ARIMA (p, d, q) * (P, D, Q)s that could be written as:

$$
\begin{gathered}
\phi_{p}(L) \phi_{p}{ }^{S}\left(L^{S}\right)\left(1-L^{S}\right)^{D}(1-L)^{d} y_{t}=\theta_{q}(L) \theta_{q}{ }^{S}\left(L^{S}\right) \varepsilon_{t} \\
\phi_{p}{ }^{S}\left(L^{S}\right)=1-\phi_{1}{ }^{S} L^{S}-\ldots-\phi_{p}{ }^{S} L^{S P} \\
\theta_{q}{ }^{S}\left(L^{S}\right)=1+\theta_{q}{ }^{S} L^{S}+\ldots+\theta_{q}{ }^{S} L^{S Q}
\end{gathered}
$$

Where $\phi_{p}(L), \theta_{q}$ are as before, $\mathrm{s}$ is the seasonal period and $\mathrm{D}$ is the number of times the seasonal difference operator (1- $\left.L^{S}\right)$ is applied. Building an ARIMA model consists of four systematic stages (identification, estimation, diagnostic check, and application or forecast) (Hossen S.M. et al., 2020).

\section{The SANCOVA model}

Any regression model which contains the quantitative and qualitative variables together is called analysis of covariance (ANCOVA) model. These ANCOVA models are the augmentation of ANOVA models. This technique provides a statistically controlling effect of quantitative regresses control variables. To find out the impact of different seasons on tourists' arrival, we proposed a modified ANCOVA model named seasonal analysis of covariance (SANCOVA). One of the significant advantages of this model over other regression model is with it, we can measure not only the relationship and partial effect of the independent variable but also can compare the qualitative effect of the independent variable. At first, we divided the temperature data into three consecutive seasons, namely winter/cool, summer/dry, and rainy/wet seasons. Each season contains the average of the average temperature of seven tourists' spots in the respective season. Realizing the limitations of data availability, only three variables are considered in the present research. For finding the relation between tourists' arrival and seasonal effect, in that case, the arrival of tourists is taken as the dependent (endogenous) variable and three seasons are considered as independent (exogenous) variables. In this model number of variables must be included depending on the nature of the phenomenon and the purpose of the research under consideration. In this study total tourists' arrival is quantitative variables together with three seasons the climatic variables are considered qualitative variables. To find the seasonal effect on tourists' arrival, we consider the dummy variable for three seasons. So, we consider the seasonal analysis of the covariance (SANCOVA) model in the present analysis. Therefore, our proposed seasonal dummy variable regression model is as follows.

Let us consider our desire classical linear regression model,

$$
\begin{aligned}
& \text { Tourists }_{i t}=\beta_{0}+\beta_{1} A V G(D+C+\operatorname{Cox}+\operatorname{Ran}+K+\operatorname{Raj}+S) \sum_{i=1}^{n} \text { Wet }(\text { June }- \text { October }) \\
& +\beta_{2} A V G(D+C+\operatorname{Cox}+\operatorname{Ran}+K+\operatorname{Raj}+S) \sum_{i=1}^{n} \operatorname{Cool}(\text { November }- \text { February })+\beta_{3} A V G(D+C+C o x+\operatorname{Ran} \\
& +K+\operatorname{Raj}+S) \sum_{i=1}^{n} \operatorname{Dry}(\text { March }- \text { May })+u_{i t} \ldots(6) \\
& Y_{t}=\beta_{0}+\beta_{1} S_{1}+\beta_{2} S_{2}+\beta_{3} S_{3}+u_{t} \ldots(7)
\end{aligned}
$$

Where, $Y_{\mathrm{t}}=$ Tourist arrival

$\beta_{0}=$ Intercept,

$\beta_{1}=$ coefficient of Season $1 /$ Wet temperature,

$$
\begin{aligned}
\mathrm{AVG}= & \text { Average } \\
& \mathrm{D}=\text { Dhaka, } \quad \text { Raj }=\text { Rajshahi, } \\
& \mathrm{C}=\text { Chittagong, }
\end{aligned}
$$


$\beta_{2}=$ coefficient of Season 2/Cool temperature

$\beta_{3}=$ coefficient of Season 3/Dry temperature,

$u_{t}=$ error terms
Cox $=$ Cox's Bazar, $\quad S_{1}=$ Wet season,

Ran = Rangamati, $\quad \mathrm{S}_{2}=$ Cool season,

$\mathrm{K}=$ Khulna, $\quad \mathrm{S}_{3}=$ Dry season,

From equation (7) our proposed SANCOVA model is, $Y_{t}=\beta_{0}+D_{1} S_{1}+D_{2} S_{2}+D_{3} S_{3}+u_{t}$

Where, $Y_{t}=$ Tourist arrival; $\beta_{0}=$ Intercept; $\left.\left.\left.\quad \begin{array}{c}D_{1}=\begin{array}{l}1, \text { when Season } 1 \\ 0, \text { otherwise }\end{array}\end{array}\right\} ; D_{2}=\begin{array}{l}1, \text { when Season } 2 \\ 0, \text { otherwise }\end{array}\right\} ; \begin{array}{l}D_{3}=\begin{array}{l}1, \text { when Season } 3 \\ 0, \text { otherwise }\end{array}\end{array}\right\}$ $u_{t}=$ error terms; $D_{1}, D_{2}, D_{3}$ are reference category

\section{DISCUSSIONS}

\section{Model Identification}

To check if the data is stationary and if there is any seasonality by which the data series were analyzed. Graphical analysis, Correlogram, and Unit root tests are used to test the stationarity of the time-series data. Dickey-Fuller (DF) and Augmented Dickey-Fuller (ADF) test is widely used to check the stationarity. If the series has no trend and the error terms are autocorrelated, then we cannot apply the Dickey-Fuller test. Another test of stationarity is Kwiatkowski-Philips-Schmidt-Shin (KPSS) and Phillips-Perron (PP) test was used. The test results for the different stations are given in Table1. To identify the suitable Autoregressive Integrated Moving Average (ARIMA) model, we use the Autocorrelation Function (ACF) and Partial Autocorrelation Function (PACF). From the ACF, we can count the number of significant autocorrelations, which is a useful estimate of the number of Moving Average (MA) coefficients in the model. On the other hand, from the PACF plot, we found the number of Autoregressive (AR) coefficients in an ARIMA model.

Table 1. Different test results for stationary

\begin{tabular}{|c|c|c|c|c|c|c|c|c|c|}
\hline \multirow{3}{*}{ Sampling Station } & \multicolumn{9}{|c|}{ Unit Root test } \\
\hline & \multirow{2}{*}{$\mathrm{ADF}$} & \multirow{2}{*}{ P-value } & \multirow{2}{*}{$\begin{array}{l}\text { Elliott-Rothenberg-Stock } \\
\text { DF-GLS test statistic }\end{array}$} & \multirow{2}{*}{$\begin{array}{l}\text { Phillips-Perron } \\
\text { test statistic }\end{array}$} & \multirow{2}{*}{ P-value } & \multicolumn{4}{|c|}{ Kwiatkowski-Phillips-Schmidt-Shin test } \\
\hline & & & & & & test statistic* & $1 \%$ level & $5 \%$ level & $10 \%$ level \\
\hline Chittagong (max) & -2.728 & 0.07 & -0.968 & -10.429 & 0.000 & 1.182 & 0.739 & 0.463 & 0.347 \\
\hline Cox's Bazar (max) & -2.272 & 0.182 & -0.254 & -16.303 & 0.000 & 3.307 & 0.739 & 0.463 & 0.347 \\
\hline Cox's Bazar (min) & -3.513 & 0.008 & -0.030 & -5.424 & 0.000 & 0.779 & 0.739 & 0.463 & 0.347 \\
\hline Rangamati (max) & -3.339 & 0.014 & -0.846 & -9.5308 & 0.000 & 1.233 & 0.739 & 0.463 & 0.347 \\
\hline Rangamati (min) & -3.672 & 0.005 & -0.932 & -4.790 & 0.000 & 0.922 & 0.739 & 0.463 & 0.347 \\
\hline Dhaka (max) & -4.544 & 0.0002 & -0.374 & -8.18 & 0.000 & 0.367 & 0.739 & 0.463 & 0.347 \\
\hline Dhaka (min) & -4.544 & 0.0002 & -0.374 & -8.180 & 0.000 & 0.367 & 0.739 & 0.463 & 0.347 \\
\hline Sylhet (max) & -3.599 & 0.006 & -0.415 & -9.78 & 0.000 & 1.804 & 0.739 & 0.463 & 0.347 \\
\hline Sylhet (min) & -3.301 & 0.015 & 0.160 & -4.361 & 0.000 & 1.378 & 0.739 & 0.463 & 0.347 \\
\hline Khulna (max) & -4.871 & 0.000 & -1.191 & -7.156 & 0.000 & 0.482 & 0.739 & 0.463 & 0.347 \\
\hline Khulna (min) & -3.739 & 0.004 & 0.067 & -4.633 & 0.000 & 0.406 & 0.739 & 0.463 & 0.347 \\
\hline Rajshahi (max) & -6.951 & 0.000 & -0.369 & -7.864 & 0.000 & 0.545 & 0.739 & 0.463 & 0.347 \\
\hline Rajshahi (min) & -3.804 & 0.003 & -0.357 & -4.617 & 0.000 & 0.097 & 0.739 & 0.463 & 0.347 \\
\hline
\end{tabular}

\begin{tabular}{|c|c|c|c|c|c|c|}
\hline Autocorrelation & Partial Correlation & & $A C$ & PAC & Q-Stat & Prob \\
\hline י & י & 1 & 0.351 & 0.351 & 68.327 & 0.000 \\
\hline 19 & $1 \longdiv { 1 }$ & 2 & 0.122 & -0.001 & 76.595 & 0.000 \\
\hline 1] & ינד & 3 & 0.084 & 0.047 & 80.488 & 0.000 \\
\hline 15 & i & 4 & 0.092 & 0.055 & 85.230 & 0.000 \\
\hline 白 & 卢 & 5 & 0.183 & 0.148 & 103.87 & 0.000 \\
\hline 19 & $1 \sqrt{1}$ & 6 & 0.079 & -0.042 & 107.38 & 0.000 \\
\hline$\sqrt{1}$ & . & 7 & -0.088 & -0.140 & 111.70 & 0.000 \\
\hline . 1 & 11 & 8 & -0.062 & -0.004 & 113.83 & 0.000 \\
\hline 1) & 1 & 9 & -0.024 & -0.004 & 114.15 & 0.000 \\
\hline 1$]$ & 11 & 10 & -0.001 & -0.009 & 114.15 & 0.000 \\
\hline $\mathrm{C}_{1}$ & d. & 11 & -0.123 & -0.141 & 122.72 & 0.000 \\
\hline , & $\square$, & 12 & -0.457 & -0.408 & 241.03 & 0.000 \\
\hline 兄, & ص日 & 13 & -0.150 & 0.200 & 253.76 & 0.000 \\
\hline 四 & $\sqrt{11}$ & 14 & -0.042 & 0.008 & 254.77 & 0.000 \\
\hline 11 & 16 & 15 & 0.004 & 0.047 & 254.77 & 0.000 \\
\hline 1.1 & ip & 16 & 0.023 & 0.067 & 255.08 & 0.000 \\
\hline d & $\sqrt{17}$ & 17 & -0.061 & 0.053 & 257.21 & 0.000 \\
\hline g. & , & 18 & -0.071 & -0.058 & 260.11 & 0.000 \\
\hline 11 & 四 & 19 & 0.022 & -0.050 & 260.38 & 0.000 \\
\hline 1.1 & 11 & 20 & 0.018 & -0.019 & 260.56 & 0.000 \\
\hline 1.1 & 1 . & 21 & 0.003 & -0.003 & 260.57 & 0.000 \\
\hline 101 & , & 22 & -0.055 & -0.058 & 262.33 & 0.000 \\
\hline . & , & 23 & -0.083 & -0.133 & 266.32 & 0.000 \\
\hline . & $\theta_{1}$ & 24 & -0.065 & -0.279 & 268.77 & 0.000 \\
\hline 14 & קי & 25 & -0.033 & 0.133 & 269.39 & 0.000 \\
\hline 11 & 1] & 26 & 0.024 & 0.094 & 269.71 & 0.000 \\
\hline d. & $\sqrt{1}$ & 27 & -0.059 & -0.053 & 271.75 & 0.000 \\
\hline 四 & 12 & 28 & -0.051 & 0.088 & 273.24 & 0.000 \\
\hline 14 & י1/ & 29 & -0.026 & 0.036 & 273.63 & 0.000 \\
\hline 11 & 1 & 30 & 0.020 & -0.005 & 273.87 & 0.000 \\
\hline 16 & 10 & 31 & 0.013 & -0.043 & 273.97 & 0.000 \\
\hline 11 & 14 & 32 & -0.011 & -0.038 & 274.05 & 0.000 \\
\hline 1) & 111 & 33 & -0.040 & -0.023 & 274.99 & 0.000 \\
\hline 11 & (1) & 34 & -0.006 & -0.045 & 275.01 & 0.000 \\
\hline ib & 1 1 & 35 & 0.061 & -0.048 & 277.18 & 0.000 \\
\hline 15 & , & 36 & 0.086 & -0.139 & 281.54 & 0.000 \\
\hline
\end{tabular}

Figure 2 (a). The time series plot of temperature for Cox's Bazar is shown with ACF and PACF plots before regular difference

\begin{tabular}{|c|c|c|c|c|c|c|}
\hline Autocorrelation & Partial Correlation & & $A C$ & PAC & Q-Stat & Prob \\
\hline $1 / 1$ & 111 & 1 & 0.006 & 0.006 & 0.0170 & \\
\hline 10 & 11 & 2 & -0.025 & -0.025 & 0.3510 & \\
\hline 111 & 1]1 & 3 & 0.013 & 0.013 & 0.4394 & \\
\hline 11 & 11 & 4 & 0.003 & 0.002 & 0.4444 & \\
\hline קי & p & 5 & 0.110 & 0.110 & 6.9852 & \\
\hline 111 & $1 \sqrt{1}$ & 6 & 0.020 & 0.019 & 7.2082 & 0.007 \\
\hline ¿ & d & 7 & -0.092 & -0.087 & 11.798 & 0.003 \\
\hline 1 & 1 & 8 & -0.051 & -0.054 & 13.230 & 0.004 \\
\hline 1$]_{1}$ & 1]1 & 9 & 0.008 & 0.003 & 13.265 & 0.010 \\
\hline 111 & 11 & 10 & 0.015 & 0.004 & 13.389 & 0.020 \\
\hline 11 & 11 & 11 & -0.016 & -0.018 & 13.534 & 0.035 \\
\hline 111 & 1/ & 12 & 0.011 & 0.032 & 13.604 & 0.059 \\
\hline 10 & 14 & 13 & -0.058 & -0.046 & 15.488 & 0.050 \\
\hline 11 & 11 & 14 & -0.012 & -0.019 & 15.572 & 0.076 \\
\hline 111 & 11 & 15 & 0.022 & 0.008 & 15.832 & 0.105 \\
\hline 1 & 19 & 16 & 0.055 & 0.060 & 17.535 & 0.093 \\
\hline 1 & 1 & 17 & 0.002 & 0.002 & 17.537 & 0.130 \\
\hline 1 1 & 101 & 18 & -0.041 & -0.032 & 18.460 & 0.141 \\
\hline 11 & 1] & 19 & 0.000 & 0.005 & 18.460 & 0.187 \\
\hline 11 & 1 & 20 & 0.014 & 0.003 & 18.572 & 0.234 \\
\hline 1 & 11 & 21 & 0.002 & -0.018 & 18.574 & 0.291 \\
\hline 10 & 10 & 22 & -0.033 & -0.035 & 19.182 & 0.318 \\
\hline 1. 1 & 101 & 23 & -0.047 & -0.026 & 20.407 & 0.310 \\
\hline 11 & 11 & 24 & -0.013 & -0.009 & 20.496 & 0.365 \\
\hline 1 & ום & 25 & -0.050 & -0.059 & 21.900 & 0.346 \\
\hline 11 & 11 & 26 & -0.012 & -0.015 & 21.985 & 0.400 \\
\hline 11 & 11 & 27 & -0.008 & 0.002 & 22.017 & 0.459 \\
\hline 11 & 11 & 28 & -0.018 & -0.009 & 22.207 & 0.508 \\
\hline 11 & 11 & 29 & -0.012 & -0.011 & 22.286 & 0.562 \\
\hline 11 & 111 & 30 & -0.009 & -0.003 & 22.331 & 0.617 \\
\hline 11 & 11 & 31 & -0.007 & -0.011 & 22.359 & 0.669 \\
\hline וקו & 111 & 32 & 0.036 & 0.024 & 23.117 & 0.679 \\
\hline 1 & 10 & 33 & -0.036 & -0.042 & 23.880 & 0.688 \\
\hline 1 & 11 & 34 & 0.008 & 0.016 & 23.919 & 0.733 \\
\hline יון ו & 16 & 35 & 0.057 & 0.055 & 25.819 & 0.684 \\
\hline 1 & 19 & 36 & 0.060 & 0.054 & 27.900 & 0.626 \\
\hline
\end{tabular}

Figure 2 (b). The time series plot of temperature for Cox's Bazar is shown with ACF and PACF plots after taking the first difference 
For example, the time series plot of Cox's Bazar station is shown with ACF and PACF plots in Figure 2(a). In Figure 2(b), we observed that AR and MA move in opposite directions having exponential decay. After taking the first difference, both ACF and PACF show a rapid decline and all the spikes are in standard error bounce. So, the series becomes stationary and it is an ARIMA model with the presence of seasonality in the time series data. For model identification, we take the seasonal difference. The seasonal difference of a time series is the series of changes from one season to the next. We have monthly data, in which there are 12 periods in a season, the seasonal difference of $y_{\text {at period t is }} y_{t}-y_{t-12}$. Which is denoted by $\nabla_{12} y_{t}$. Where $\nabla_{12} y_{t}=y_{t}-y_{t-12}$.

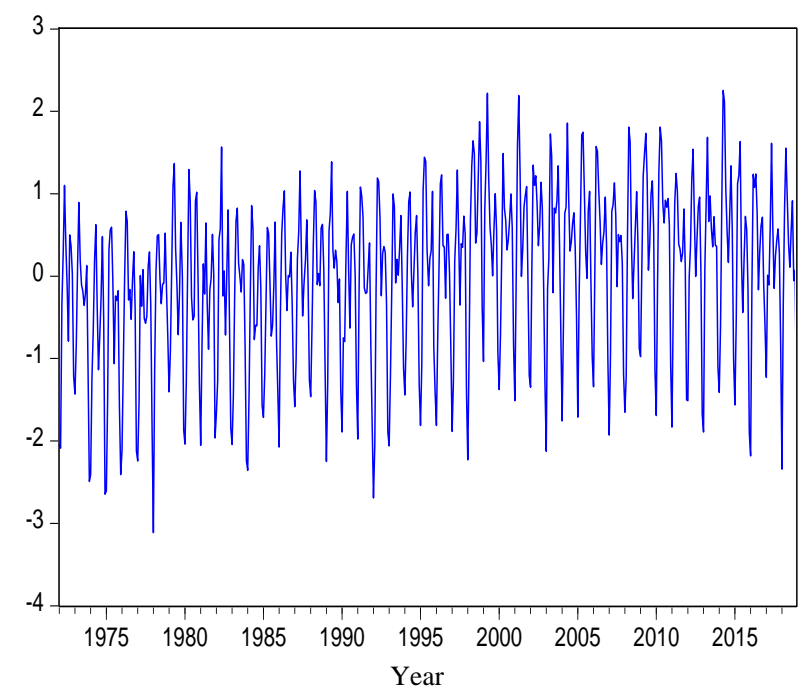

Figure 3(a). The seasonal difference of series before seasonal difference

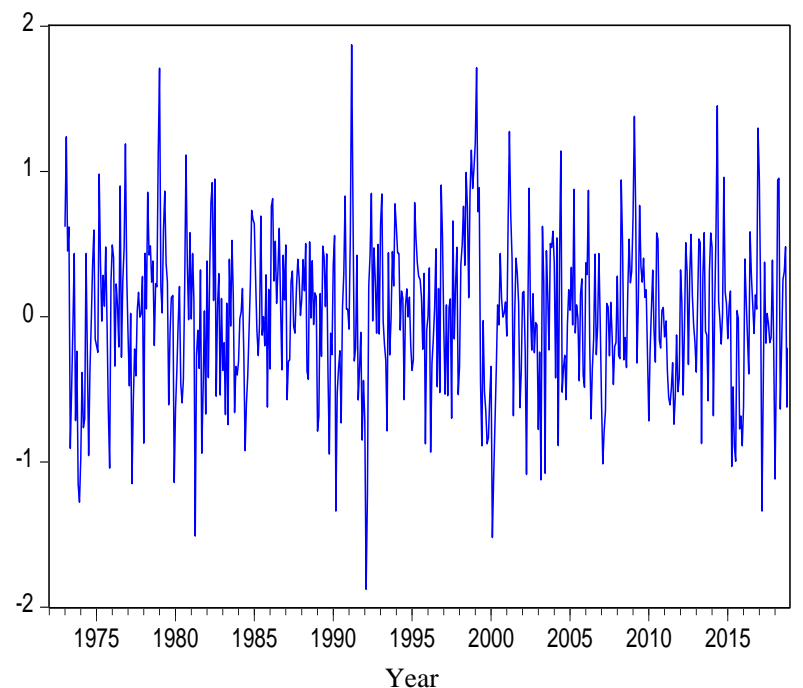

Figure 3(b). The seasonal difference ot serıes atter taking the seasonal difference

From the above Figure 3(a \& b), we show that the seasonal differenced series seems to be stationary. Now we evaluate Seasonal Autocorrelation (SAC) and Seasonal Partial Autocorrelation (SPAC) of $\nabla_{12} y_{t}$ at different lags.

Diagnostic Checking

To know about the residuals are normally distributed or not, we will check the Histogram and Normality test. The Jarque-Bera test of normality is,

$$
J B=n\left[\frac{s^{2}}{\sigma}+\frac{(k-3)^{2}}{24}\right]
$$

Where, $n=$ sample size, $s=$ skewness, and $k=$ kurtosis.

Histogram and Jarque-Bera test results (shown in Table 2) indicate that the residual is normally distributed. Therefore, the test results suggest that the model is fully specified.

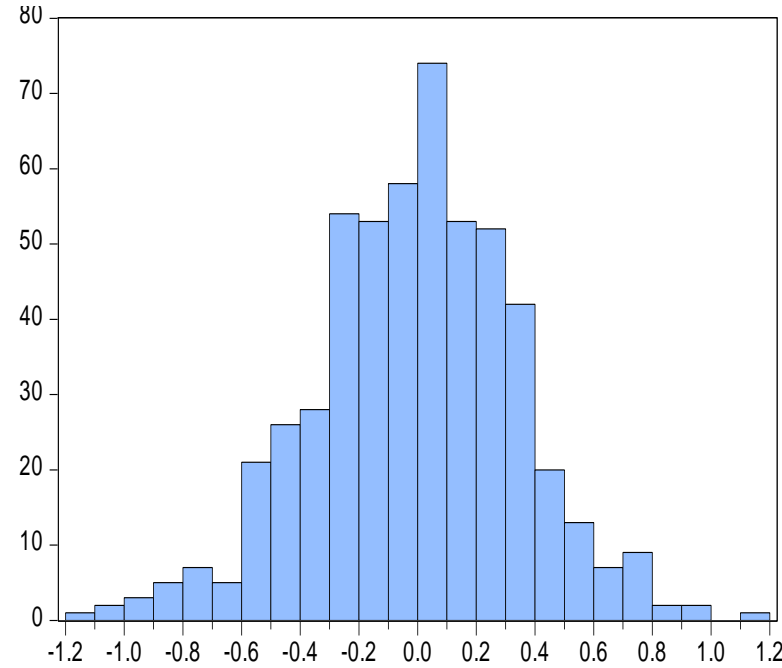

Figure 4. Histogram and Normality checking

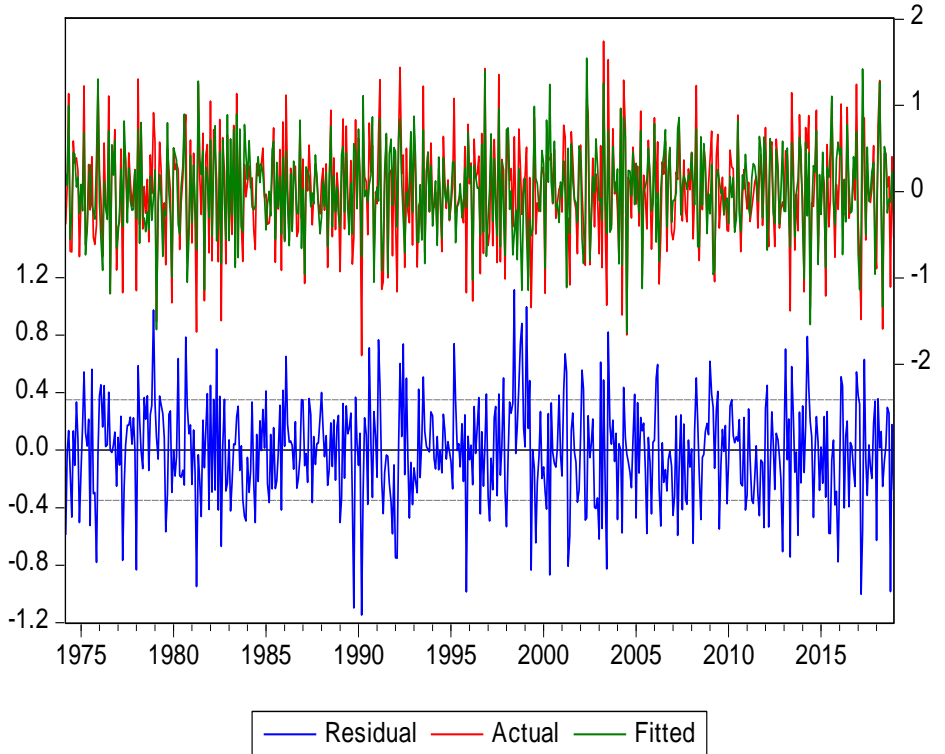

Figure 5. Actual fitted and residual plot for SARIMA SARIMA $(1,1,1) \times(1,1,2)_{12}$

From Figure 4 and 5, it is observed that autocorrelation and Q-test for different lags support the hypothesis that there is no autocorrelation in the residual. Thus, the model is fully specified. 


\section{Modelling}

For the presence of seasonality, with the help of Box-Jenkins (1976) and modified by Box et al. (2019) model building process, we have built the SARIMA model for the monthly temperature of seven geographically diverse locations in Bangladesh. There are a variety of statistical measures of forecasting error, mostly based on an average of the errors between the actual and forecast values at time $t$. They are:

Mean Absolute Error (MAE):

$M A E=\frac{1}{T} \sum_{1}^{T}\left|Y_{\text {actual }}-Y_{\text {forecast }}\right|$

Root Mean Squared Error (RMSE): $\quad R M S E=\sqrt{\frac{\sum_{1}^{T}\left(Y_{\text {actual }}-Y_{\text {forecast }}\right)^{2}}{\sum_{1}^{T}\left(Y_{\text {actual }}-\bar{Y}\right)^{2}}}$

Mean Absolute Percentage Error (MAPE): $\quad M A P E=\frac{1}{T} \sum_{1}^{T}\left|\frac{Y_{\text {actual }}-Y_{\text {forecast }}}{Y_{\text {actual }}}\right| \times 100 \%$

For which model we get the lowest mean square error, we take the model as the best model. We use the best model for forecasting those are shown in Table 2.

Table 2. Different SARIMA models for different tourists' stations

\begin{tabular}{|c|c|c|c|c|c|c|c|}
\hline & & \multicolumn{4}{|c|}{ Model Fit statistics } & \multirow[b]{2}{*}{ Jarque -Bera } & \multirow[b]{2}{*}{ P-value } \\
\hline Station & Model & R-squared & RMSE & MAE & MAPE & & \\
\hline Chittagong (Max) & $\operatorname{SARIMA}(1,1,1) \times(0,1,1)_{12}$ & 0.602 & 0.503 & 0.407 & 164.563 & 224.806 & 0.000 \\
\hline Chittagong (Min) & SARIMA $(1,1,1) \times(0,1,1) 12$ & 0.679 & 0.184 & 0.126 & 31.063 & 441.577 & 0.000 \\
\hline Cox's Bazar (Max) & $\operatorname{SARIMA}(1,1,1) \times(1,1,2)_{12}$ & 0.672 & 0.471 & 0.314 & 71.491 & 5.983 & 0.050 \\
\hline Cox’s Bazar (Min) & SARIMA $(1,0,0) \times(0,1,1)_{12}$ & 0.536 & 0.199 & 0.138 & 23.895 & 59.924 & 0.000 \\
\hline Rangamati (Max) & SARIMA $(1,1,1) \times(0,1,1)_{12}$ & 0.677 & 0.349 & 0.258 & 260.301 & 45.225 & 0.000 \\
\hline Rangamati (Min) & SARIMA $(1,0,1) \times(0,1,1) 12$ & 0.534 & 0.199 & 0.146 & 26.259 & 21.441 & 0.000 \\
\hline Dhaka (Max) & $\operatorname{SARIMA}(2,0,1) \times(0,1,1)_{12}$ & 0.546 & 0.319 & 0.249 & 394.467 & 39.465 & 0.000 \\
\hline Dhaka (Min) & SARIMA $(1,0,1) \times(0,1,1)_{12}$ & 0.548 & 0.320 & 0.251 & 39.753 & 25.915 & 0.000 \\
\hline Sylhet (Max) & SARIMA $(1,0,0) \times(2,1,1)_{12}$ & 0.579 & 0.468 & 0.371 & 75.682 & 14.487 & 0.001 \\
\hline Sylhet (Min) & SARIMA $(2,1,2) \times(0,1,1){ }_{12}$ & 0.685 & 0.165 & 0.128 & 65.052 & 34.035 & 0.000 \\
\hline Khulna (Max) & SARIMA $(1,0,0) \times(0,1,1)_{12}$ & 0.510 & 0.289 & 0.230 & 48.586 & 73.913 & 0.000 \\
\hline Rajshahi (Max) & SARIMA $(0,0,1) \times(1,1,2)_{12}$ & 0.314 & 0.263 & 0.369 & 90.721 & 54.701 & 0.000 \\
\hline Rajshahi (Min) & SARIMA $(2,0,1) \times(0,1,1)$ ) & 0.433 & 0.156 & 0.122 & 20.166 & 19.475 & 0.000 \\
\hline
\end{tabular}

\section{Estimation of SANCOVA model}

Estimating the impact of seasonal effect on tourist's arrival we get the following Table 3.

Here, the multiple coefficients of determination $\left(R^{2}\right)$ is 0.74 . This result suggests that the independent variable explained the dependent variable by $74 \%$ of the total variation. That is seasonality has a $74 \%$ effect on tourist's arrival in Bangladesh. In Table 4 , the multiple coefficients of determination $\left(R^{2}\right)$ for all reference category is 0.98 . This result suggests that the independent variable explained the dependent variable by $98 \%$ of the total variation. That is seasonality has a $98 \%$ effect on overall temperature in Bangladesh.

Table 3. Seasonal effect on tourists' arrival

\begin{tabular}{|c|c|c|c|c|c|}
\hline Model & Standardized Coefficients & t statistic & $\mathrm{P}$-value & $\bar{R}$ & $\bar{R}^{-}$ \\
\hline Season 1 & -0.042 & -0.077 & 0.951 & \multirow{3}{*}{0.860} & \multirow{3}{*}{0.740} \\
\hline Season 2 & -1.174 & -1.610 & 0.354 & & \\
\hline Season 3 & 0.898 & 1.224 & 0.436 & & \\
\hline
\end{tabular}

Table 4. Seasonal effect on annual Temperature
\begin{tabular}{|l|l|l|l|l|l|l|}
\hline Reference category & $R^{2}$ & $B_{0}$ & $B_{1}$ & $D_{2}$ & $D_{3}$ \\
\hline Winter & 0.992 & 0.983 & 22.14 & & 0.918 & 1.052 \\
\hline Dry & 0.992 & 0.983 & 29.02 & -0.918 & & 0.134 \\
\hline Wet & 0.992 & 0.983 & 28.15 & -1.052 & -0.134 & \\
\hline
\end{tabular}

\section{Findings from the SARIMA model}

Time series analysis and forecasting have become a major tool in numerous applications in meteorology and other environmental areas to understand phenomena, like temperature, humidity, and rainfall. To show the forecasting behavior of the Climate change of Cox's Bazar in Bangladesh, we mainly study the time series data and fit the appropriate time series model and then the forecast is based on the fitted model. After getting the series stationary, then we take the seasonal differences for the presence of seasonality in the time series data. Observing ACF and PACF we have fitted as SARIMA model.

For the monthly rainfall of Cox's Bazar, we have fitted SARIMA $(1,1,1) \times(1,1,2)_{12}$ model and then estimate the parameters of the model. After getting the appropriate model we check the validity of the model using Residual diagnostics and stability tests. Normal probability plot and Jarque-Bera tests are used to check the normality of the residuals. Then we forecast up-to 2030. 
Similarly, Observing ACF and PACF have fitted as SARIMA model for monthly temperature of Chittagong (max. \& min.), Sylhet (max. \& min.), Dhaka (max. \& min.), Khulna (max. \& min.), Rajshahi (max. \& min.) and Rangamati (max. \& min.) we have fitted SARIMA $(1,1,1) \times(0,1,1) 12, \operatorname{SARIMA}(1,1,1) \times(0,1,1) 12, \operatorname{SARIMA}(1,0,0) \times(2,1,1) 12, \operatorname{SARIMA}(2,1,2) \times(0,1,1) 12, \operatorname{SARIMA}(2,0,1) \times(0,1,1) 12$, SARIMA $(1,0,1) \times(0,1,1) 12, \operatorname{SARIMA}(1,0,0) \times(0,1,1) 12, \operatorname{SARIMA}(2,0,0) \times(0,1,1) 12, \operatorname{SARIMA}(0,0,1) \times(1,1,2) 12, \operatorname{SARIMA}(2,0,1) \times(0,1,1) 12$, SARIMA $(1,1,1) \times(0,1,1) 12$ and SARIMA $(1,0,1) \times(0,1,1) 12$ model consecutively and then estimate the parameters of these model. After getting appropriate model we check the validity of the model using Residual diagnostics and stability test. Normal probability plot and Jarque-Bera test are used to check the normality of the residuals. Then we forecast up to 2030.

From the above Figure 6, we found that the maximum temperature is slightly increasing approximately $1{ }^{0} \mathrm{C}$ but decreasing approximately $2{ }^{0} \mathrm{C}$. The highest temperature will have appeared Khulna and Rajshahi with $35.53{ }^{\circ} \mathrm{C}$ and $35.85{ }^{\circ} \mathrm{C}$ respectively. It also shows that for Dhaka, Chittagong, Cox's Bazar, Khulna, and Sylhet have extreme values for decreasing temperature. This indicates that in Dhaka, the maximum temperature will be $25.14{ }^{\circ} \mathrm{C}$ on January 2023, in Chittagong $26{ }^{\circ} \mathrm{C}$ on January 2027 , Cox's Bazar $26.49{ }^{\circ} \mathrm{C}$ on January 2030 , in Khulna $25.61{ }^{\circ} \mathrm{C}$ on January 2023, and in Sylhet $26.56{ }^{\circ} \mathrm{C}$ on January 2020.

From the above Figure 7 , we found that the minimum temperature is slightly increasing approximately by $1{ }^{0} \mathrm{C}$ but decreasing approximately by $2{ }^{\circ} \mathrm{C}$. The lowest temperature appeared in Rajshahi and Rangamati with $10.40{ }^{\circ} \mathrm{C}$ and $11.72{ }^{\circ} \mathrm{C}$ respectively. It also shows that Dhaka has extreme values for decreasing temperature. This indicates that in Dhaka the minimum temperature will be $12.48{ }^{0} \mathrm{C}$ in January 2023 whereas the lowest temperature in Dhaka is $13.08{ }^{\circ} \mathrm{C}$.

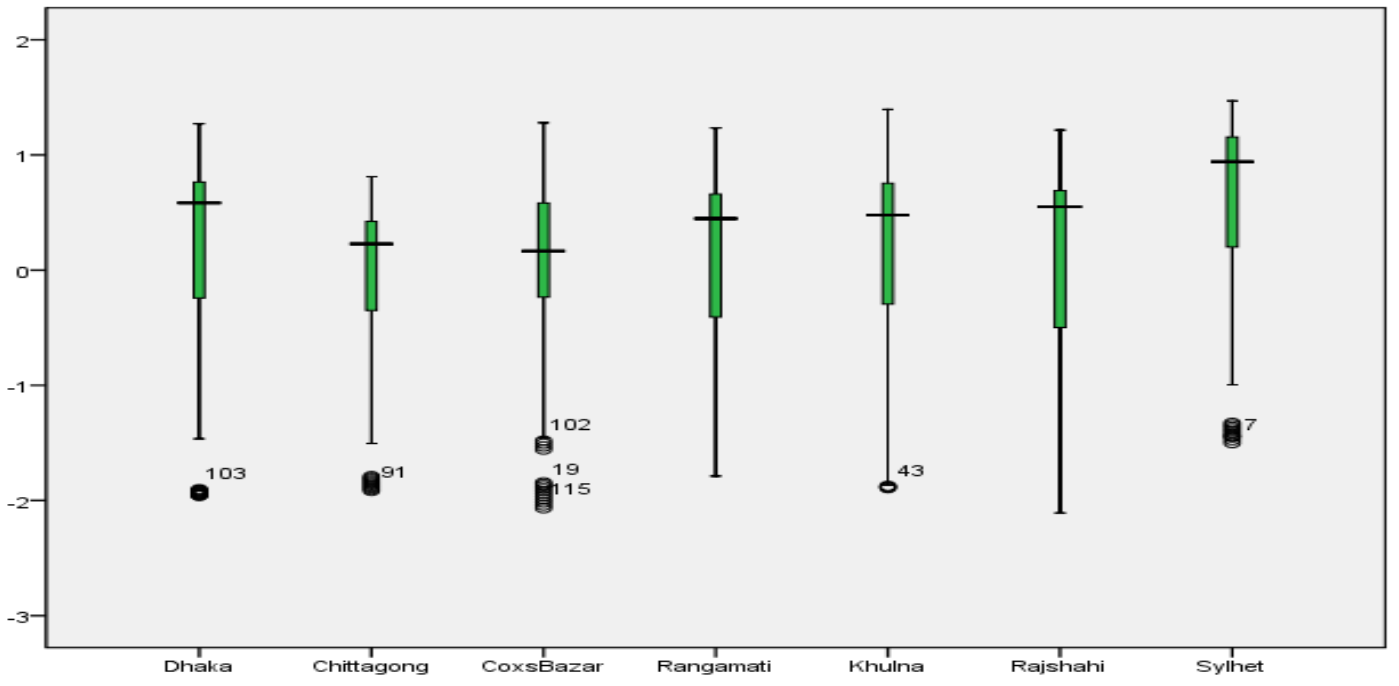

Figure 6. Comparison of forecasted maximum temperature between different tourists' stations

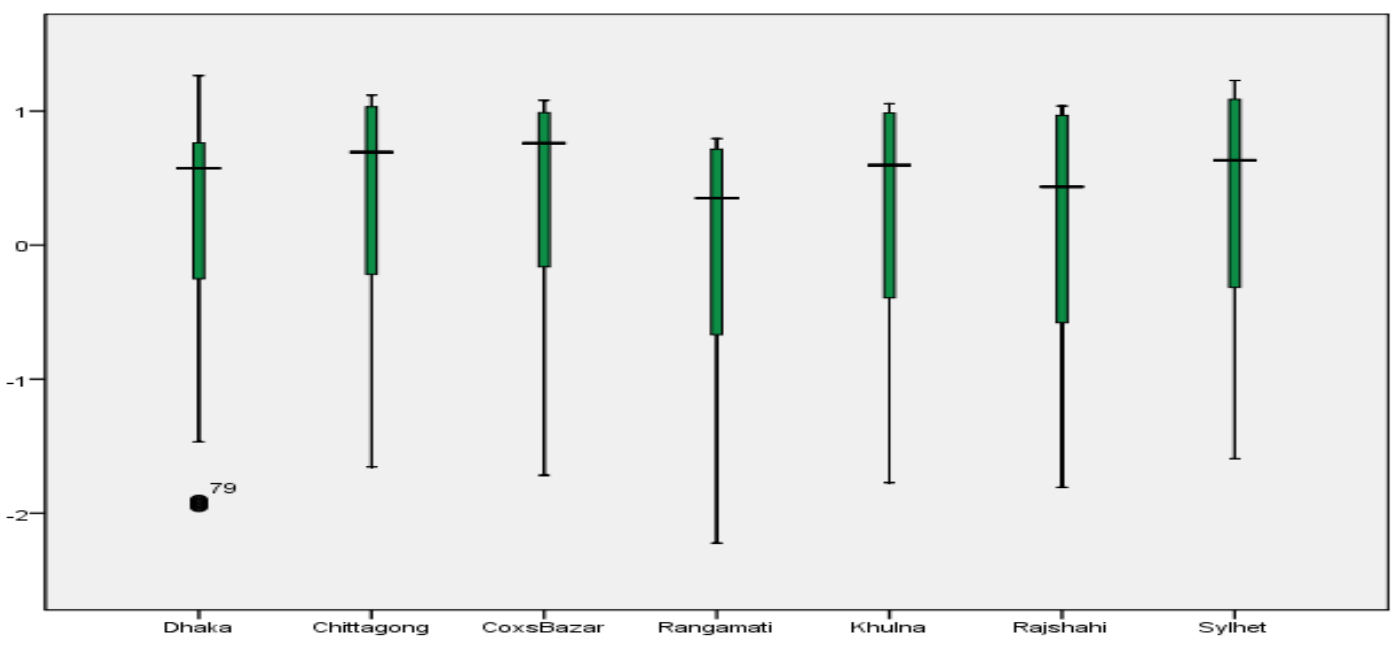

Figure 7. Comparison of forecasted minimum temperature between different tourists' stations

\section{Findings from SANCOVA model}

Here in the analysis, we found that the multiple coefficients of determination $\left(R^{2}\right)$ for seasonal effect on tourists' arrival. is 0.74 and for seasonal effect on annual temperature is 0.98 . This result suggests that the total seasonality has a $74 \%$ effect on tourist's arrival in Bangladesh. This result also reveals that seasonality has a $98 \%$ effect on overall temperature in Bangladesh.

\section{Considering Winter season as the reference category}

The mean value of the reference category is representing by $\beta_{0}$ called intercept term i.e., winter season. The intercept value $\beta_{0}$ represents the mean value of the reference category, i.e.; winter season. Hence, in the present analysis, the intercept value of the regression model is about $22.14^{0} \mathrm{C}$, represents the mean temperature in the winter season.

$\beta_{2}$ tells us the mean temperature in the summer season is greater about $0.918{ }^{0} \mathrm{C}$ than the mean temperature of the reference category, winter season. $\beta_{3}$ provides the result that the mean temperature in the wet season is higher about $1.052{ }^{0} \mathrm{C}$ than the mean temperature of the reference category, winter season. 


\section{CONCLUSIONS}

The temperature forecast is critical in Bangladesh because of its spatiotemporal variation and non-linear pattern in size. However, the estimation of temperature is urgency in Bangladesh for harvesting rainwater, flood management, water resource management, urban planning, and maximizing the irrigation system operation. In the present study, the SARIMA model was utilized to predict the temperature forecast in seven tourisms attraction in Bangladesh. The highest and the lowest $\mathrm{R}^{2}$ values were determined to be 0.685 and 0.314 in Sylhet and Rajshahi, respectively. This indicates that the developed SARIMA models accurately describe the temperature forecast in Bangladesh. This finding reveals that the developed SARIMA models could be utilized as a reliable mathematical tool to determine the temperate forecasting. The finding of this present study suggests that the SARIMA model can be used to carry out having more climatic parameters like wind speed and direction, wind pressure, drought, sea-level rise, solar radiation, and their impacts on human activity. Our findings also indicate that the tourism industry of Bangladesh is more vulnerable to seasonal variation and this seasonality has a 74\% effect on tourist's arrival in Bangladesh. So, we can conclude that our proposed modified ANCOVA modeling named SANCOVA is better than any other regression model in the case of evaluating the seasonal effect on the national economy. It would be applicable and also possible to study climatic variables of a specific region of the country or in a specific season. The study also can carry out to estimate the effect of the climatic variable on tourist arrival, crop productions, and food security.

\section{REFERENCES}

Becken, S., Zammit, C., \& Hendrikx, J. (2015). Developing Climate Change Maps for Tourism: Essential Information or Awareness Raising? Journal of Travel Research, 54(4), 430-441. https://doi.org/10.1177/0047287514528286

Chen, C.M., Lin, Y.L., \& Chang, T.T. (2017). The effects of macroeconomic and weather conditions on the business cycle of Taiwan's adventure tourism. Current Issues in Tourism, 20(5), 447-454. https://doi.org/10.1080/13683500.2016.1187584

Dube, K., \& Nhamo, G. (2018). Climate variability, change and potential impacts on tourism: Evidence from the Zambian side of the Victoria Falls. Environmental Science and Policy, 84(4), 113-123. https://doi.org/10.1016/j.envsci.2018.03.009

Fang, Y., \& Yin, J. (2015). National assessment of climate resources for tourism seasonality in China using the tourism climate index. Atmosphere, 6(2), 183194. https://doi.org/10.3390/atmos6020183

Fyfe, J., Bent, R., \& Seaman, C. (2020). Business internet use in small, family owned and managed hotels in Scotland. International Journal of Business and Globalisation, 24(2), 256-274. https://doi.org/10.1504/IJBG.2020.105171

Grillakis, M.G., Koutroulis, A.G., Seiradakis, K.D., \& Tsanis, I.K. (2016). Implications of $2{ }^{\circ} \mathrm{C}$ global warming in European summer tourism. Climate Services, 1, 30-38. https://doi.org/10.1016/j.cliser.2016.01.002

Hewer, M., Scott, D., \& Fenech, A. (2016). Seasonal weather sensitivity, temperature thresholds, and climate change impacts for park visitation. Tourism Geographies, 18(3), 297-321. https://doi.org/10.1080/14616688.2016.1172662

Hoogendoorn, G., \& Fitchett, J.M. (2018). Tourism and climate change: a review of threats and adaptation strategies for Africa. Current Issues in Tourism, 21(7), 742-759. https://doi.org/10.1080/13683500.2016.1188893

Jedd, T.M., Hayes, M.J., Carrillo, C.M., Haigh, T., Chizinski, C.J., \& Swigart, J. (2018). Measuring park visitation vulnerability to climate extremes in U.S. Rockies National Parks tourism. Tourism Geographies, 20(2), 224-249. https://doi.org/10.1080/14616688.2017.1377283

Kovács, A., Unger, J., Gál, C.V., \& Kántor, N. (2016). Adjustment of the thermal component of two tourism climatological assessment tools using thermal perception and preference surveys from Hungary. Theoretical and Applied Climatology, 125(1-2), 113-130. https://doi.org/10.1007/s00704-015-1488-9

Li, H., Goh, C., Hung, K., \& Chen, J.L. (2018). Relative Climate Index and Its Effect on Seasonal Tourism Demand. Journal of Travel Research, 57(2), 178192. https://doi.org/10.1177/0047287516687409

Li, H., Song, H., \& Li, L. (2017). A Dynamic Panel Data Analysis of Climate and Tourism Demand: Additional Evidence. Journal of Travel Research, 56(2), 158-171. https://doi.org/10.1177/0047287515626304

Naing, W.Y.N., \& Htike, Z.Z. (2015). Forecasting of monthly temperature variations using random forests. ARPN Journal of Engineering and Applied Sciences, 10(21), 10109-10112.

Nury, A.H., Hasan, K., \& Alam, M.J. Bin. (2017). Comparative study of wavelet-ARIMA and wavelet-ANN models for temperature time series data in northeastern Bangladesh. Journal of King Saud University - Science, 29(1), 47-61. https://doi.org/10.1016/j.jksus.2015.12.002

Pablo-Romero, M. del P., Pozo-Barajas, R., \& Sánchez-Rivas, J. (2017). Relationships between tourism and hospitality sector electricity consumption in Spanish Provinces (1999-2013). Sustainability (Switzerland), 9(4). https://doi.org/10.3390/su9040480

Pasetto, D., Finger, F., Rinaldo, A., \& Bertuzzo, E. (2017). Real-time projections of cholera outbreaks through data assimilation and rainfall forecasting. Advances in Water Resources, 108, 345-356. https://doi.org/10.1016/j.advwatres.2016.10.004

Patowary, A.N. (2017). Monthly Temperature Prediction Based on Arima Model: a Case Study in Dibrugarh Station of Assam, India. International Journal of Advanced Research in Computer Science, 8(8), 292-298. https://doi.org/10.26483/ijarcs.v8i8.4590

Pintassilgo, P., Rosselló, J., Santana-Gallego, M., \& Valle, E. (2016). The economic dimension of climate change impacts on tourism: The case of Portugal. Tourism Economics, 22(4), 685-698. https://doi.org/10.1177/1354816616654242

Pratiher, S., Mukhopadhyay, S., Barman, R., Pratiher, S., Dey, S., Banerjee, S., \& Panigrahi, P.K. (2016). Recurrence quantification \& ARIMA based forecasting of rainfall-temperature dynamics. 2016 International Conference on Signal Processing and Communication, ICSC 2016, 490-495. https://doi.org/10.1109/ICSPCom.2016.7980630

Priego, F.J., Rosselló, J., \& Santana-Gallego, M. (2015). The impact of climate change on domestic tourism: a gravity model for Spain. Regional Environmental Change, 15(2), 291-300. https://doi.org/10.1007/s10113-014-0645-5

Scott, D., Rutty, M., Amelung, B., \& Tang, M. (2016). An inter-comparison of the Holiday Climate Index (HCI) and the Tourism Climate Index (TCI). Europe. Atmosphere, 7(6), 23-28. https://doi.org/10.3390/atmos7060080

Wilkins, E., de Urioste-Stone, S., Weiskittel, A., \& Gabe, T. (2018). Effects of Weather Conditions on Tourism Spending: Implications for Future Trends under Climate Change. Journal of Travel Research, 57(8), 1042-1053. https://doi.org/10.1177/0047287517728591

Zhang, H.Q., \& Kulendran, N. (2017). The Impact of Climate Variables on Seasonal Variation in Hong Kong Inbound Tourism Demand. Journal of Travel Research, 56(1), 94-107. https://doi.org/10.1177/0047287515619692

Hossen S.M., Hossain M.T., Chakraborty A., \& Ismail M.T. (2020). Modeling for Prospect of Aman Rice Production in Dhaka Division, Bangladesh. Rahman A. (eds) Statistics for Data Science and Policy Analysis. Springer, Singapore. https://doi.org/10.1007/978-981-15-1735-8 6

Witchayakawin, P., Chantanupan, R., \& Tabash, M.I. (2020). Impacts and benefits from tourism an example from Thailand. GeoJournal of Tourism and Geosites, 32(4), 1270-1276. https://doi.org/10.30892/gtg.32412-568

*** Box GEP, Gwilym MJ, Gregory CR.(2019). Time Series Analysis: Time Series Analysis Forecasting \& Control. New Jersey: Prentice Hall, Englewood Cliffs

**** WTTC. (2019). Travel \& Tourism: Global Economic Impact. https://www.statista.com/statistics/233223/travel-and-tourism--total-economic-contribution-worldwide/ 